\title{
What Future? Which Technology? On the Problem of Describing Relevant Futures
}

\author{
Bernd Carsten Stahl \\ Centre for Computing and Social Responsibility, Department of Informatics, \\ De Montford University, Leicester, LE1 9BH, UK \\ bstahl@dmu.ac.uk
}

\begin{abstract}
Doing research on future and emerging technologies raises a number of significant ontological and epistemological challenges. The fundamental uncertainty of the future, combined with problems of appropriate descriptions of technology in general, render it difficult to come to an appropriate account of the likely shape and use of future technologies. This paper discusses several streams of research that address this issue, including the question of relevant description and context, interpretive flexibility, affordances of technology, and multi-stability of technological trajectories. The paper proposes that some of these problems may be addressed by using a democratic and participative approach to technology research and development. Participative technology assessment is then discussed as an example of an established way of democratically engaging with technology stakeholders during research and development. The paper concludes by discussing the promises and limitations of such a participative approach with regard to the question of understanding and researching future technologies.
\end{abstract}

Keywords: Emerging ICT, epistemology, ontology, participative technology assessment.

\section{Introduction}

The core problem of researching the is that the future is, by definition, unknown. While it would doubtlessly be desirable to have certainty about the future, this can never be the case, simply because of the epistemic uncertainty of the future. The initial response to the IFIP WG8.2 conference theme "Researching the Future" is, therefore, what future? Given the rapid development of technology, the technologies that may shape the (unknown) future are unlikely to be the same we have now. This increases the uncertainty: we are now looking at unknown information technology for an unknown future. Briefly, we can know neither future information technologies nor any of the other aspects of the future. At the same time, however, we need to make decisions based on assessments of the future that will then, in turn, influence the way the future will turn out in practice. This raises a number of practical problems on an individual, organizational, and political level. These practical problems cannot be solved without due attention to the underlying philosophical issues that cause them. 
This paper addresses these core philosophical questions. It starts out with a discussion of several theoretical positions that aim to describe the theoretical uncertainty of the future, and in particular of future technologies. The paper proposes that while individuals face a number of ontological and epistemological problems when assessing the future, collectively they may be in a better position to do so. In addition, such collective perceptions of the future have the potential to provide a sound and legitimate basis for policy decisions. Drawing on the literature in participatory technology assessment (pTA), different methods are discussed that can be used to address the problem. This leads to the conclusion, which discusses the limitations of this approach and underlines its importance and implications for information systems research.

The paper's main contribution to the body of work on future technologies is its discussion of the different fundamental philosophical problems that are encountered when trying to identify emerging ICTs and provide descriptions of them. An awareness of these problems is important to understand the limitations and validity claims of about the future. In addition, the paper develops the argument that these fundamental ontological and epistemological issues can be addressed by participative methods. These methods, some of which have been discussed and used in the area of information systems for considerable time, offer what may be our best bet to come to a reasonable understanding of the future and the role ICTs can play in shaping it.

\section{Descriptions of Future Technologies}

The fact that the future is not known is not particularly surprising by itself. Aristotle's study of temporal logic was caused by the observation that statements about the future have different properties from a-temporal statements. Briefly, a statement concerning the future is, at the present moment, neither true nor false. For example, the proposition "it will rain tomorrow" may or may not be true. We can only know with certainty tomorrow. The purpose of this paper is not to explore temporal logic or the general philosophical assessment of the future but to concentrate on future technologies. This section discusses several alternative theories of why exact knowledge of future technologies is impossible. This means that general issues of uncertainty of the future, such as the fact that we don't know how a particular technology will be used in 10 years because by then the world may have come to an end, will not be discussed here. But even disregarding such general issues, there are still a number of reasons why we cannot know future technologies with certainty.

An initial conceptual clarification required here concerns the concept of technology. It is not the purpose of this paper to engage in the general philosophy of technology (Dusek 2006; Olsen et al. 2009). Characteristics of technology that one can typically find include a basis in structured thought, temporal stability and reproducibility, and a reflection in artifacts which may (but do not have to be) of a physical nature. Technologies are typically developed for specific ends. This raises the question of the relationship between technologies and their application. It is easily conceivable that a particular technological artefact can raise different questions depending on context and application of use but also on the technology's conception and representation.

Technologies are not fixed and objectively given. The position that posits such an objectivity of technology, which would allow for a straightforward prediction of uses 
and consequences on the basis of the description of the technology, is often called technological determinism. Adam (2001, p. 239) defines technological determinism as

the perspective that views developments in technology as driving society; "impacts" is the term often used. Such impacts are seen as inevitable, the relationship of technology and society is regarded as linear and monodirectional, i.e., from technology toward society.

Technological determinism is generally agreed to be conceptually misleading and empirically untenable. However, choosing a description of technology that is not determinist can lead to a number of problems. The problems with which this paper is concerned are a combination of ontological and epistemological ones. They are caused by the nature of technology (ontological) and the related issue of how we can know about it (epistemology). Some of these issues are caused by the fact that the phenomenon in question is a future one; others are equally pertinent for present technology. The paper will touch on the question of how one can know that an appropriate description of the technology in question was made. This leads to a discussion of the problem of interpretive flexibility of technology, followed by the related issue of multi-stability of technology.

All of these questions are highly theoretical and require abstract conceptualizations. In order to make it easier for the reader to follow the argument, the paper will employ one ongoing example of an emerging technology, namely ambient intelligence (AmI). AmI can be seen as an emerging technology because a significant percentage of current ICT development is invested in areas that are directly related to it. As a vision of technological developments, it has been around for several decades. The principle behind AmI is that computing technologies are removed from the perceptual foreground and blend into the background. Intelligent applications surround human agents and provide them with customized services. Wellknown examples of these ideas are the refrigerator that automatically orders missing stock from the supermarket or the intelligent house that regulates heating and lighting autonomously according to the occupiers' preferences. AmI is a technology-or maybe better, a socio-technical system-which comprises a large number of potential applications and artefacts. It is a high-level technology that has the potential to significantly affect the way humans interact with their human and nonhuman environment. For this reason it is of high social and ethical relevance. Given that it is not truly in existence at present, it can serve to exemplify the problems of description and democratic governance of technology.

\subsection{Relevant Description and Context}

Whenever researchers (or anybody else, for that matter) describe a phenomenon, they need to draw a boundary around the phenomenon in question. In this context, it is important to point out that phenomena are always human constructs. This recognition goes back to Kant (1995), who pointed out the important distinction between the thing as in itself (Noumenon) and its appearance (Phaenomenon). This distinction has been criticized by philosophers for a variety of reasons. This paper does not engage in that particular discourse but needs to make clear that it concentrates on phenomena. These 
are seen as the object of cognition and they are clearly humanmade. This is not to deny the existence of the thing in itself. Indeed, much of the following subsections are concerned with the question of how to conceptualize the relationship between thing in itself and phenomenon.

The initial question arising from the desire to describe a technology is how one can know whether the description is appropriate. The choice of the boundaries of the description of the phenomenon determines the conclusion that can be drawn from it. If, for example, one wants to conduct an analysis of a particular technology or its use or if one wants to regulate design and use, the findings will depend on the content of the description. This "problem of relevant description" (van der Hoven 2010) is not a new one in philosophy. Anscombe (1958), for example, critiqued Kant's categorical imperative as useless without stipulations concerning relevant description.

This problem of relevant description applies to any description of technical phenomena. How can an observer know whether a phenomenon under observation is appropriately described? This is a broad problem that relates to epistemology and theories of truth. This question is clearly pertinent for emerging technologies but it is similarly important for well-established technologies. The example of AmI demonstrates the problem. The earlier introduction of AmI is limited. Individuals knowledgeable in the area might focus on technical infrastructure, user interfaces, or novel devices. At the same time, one could argue that the important aspect of AmI is the way in which it models human beings or the novel types of data AmI will require and bring into existence. One could look at technical artifacts (e.g., particular sensors), subsystems (e.g., wireless sensor systems, wearable computers), socio-technical systems (e.g., the sales process of the refrigerator to order missing milk), etc. An added problem is that there will be a range of equally valid descriptions. Some positions on AmI are clearly colored, for example, the sales pitches of companies aiming to sell AmI products. They emphasize the potential strengths and tend to ignore potential weaknesses. It is clearly too simple, however, to attribute bias to vendors without acknowledging bias emanating from others. In fact, the whole issue of bias comes back to the question of what would be a correct (or true) description of the technology, which is at the core of this paper. Finally, AmI is an emerging technology, which means that it is currently not mature or widely used. AmI is surrounded by uncertainty as to possible and likely uses. This adds to the complexity and ambiguity because a description of an emerging technology cannot draw on applications and examples for evaluation.

If asked to describe the technology AmI, which of these (or additional) perspectives should be taken? And even if this question could be answered, then the immediate follow-on question would be: How do we know that the particular perspective has been described appropriately and in the level of detail and depth that is required?

The literature offers a number of conceptualizations and theories that provide conceptual tools for capturing this uncertainty of emerging technologies. Some of the more prominent ones are discussed in the following sections.

\subsection{Interpretive Flexibility}

In the field of information systems, one well-developed approach to the problem of appropriative descriptions of technology is connected with the idea of interpretive flexibility. Interpretive flexibility denotes the property of technology of being constituted by 
use. Proponents of interpretive flexibility argue that technology is not fixed but will develop during perception and use. The tenets of interpretive flexibility are widely recognized in science and technology studies where different positions such as social study of technology (SST) or the social construction of technology hold such views (Bijker 1997; Grint and Woolgar 1997; Howcroft et al. 2004) and also in related fields such as actor-network theory (Latour 2007; Law and Hassard 1999). Some scholars distinguish between interpretive and interpretative flexibility with the former referring to the epistemological aspect of the social construction of technology and the latter being a stronger position that sees the construction as ontologically constitutive of technology (Cadili and Whitley 2005).

The concept of interpretive flexibility tends to be invoked to describe variable uses of extant technologies. It is often brought to bear against the assumption that a particular technology or IS will have specific and predictable results and uses. Technologies can be interpreted depending on context, culture, organizational environment, and many other variables. Interpretive flexibility can explain why a successful technology used in one organization does not have the same consequences in another one that looks similar in many respects.

What is less well explored, at least in the field of IS, is the question of the relationship of interpretive flexibility with future and emerging technologies. There is a direct link between emergence and interpretive flexibility. Interpretive flexibility is a function of social interaction and pertains to particular discourses. That means that a technology may emerge in one context even though it may be well established elsewhere. It also means that the same underlying artefact can emerge into different technologies in terms of usage and application.

\subsection{Affordances of Technology}

The preceding discussion of interpretive flexibility is deeply rooted in social constructivism or constructionism (Gergen 1999). Social constructivism pervades much of science and technology studies and has been a strong answer to determinist positions (Grint and Woolgar 1997). One strong opposing argument against social constructivism is that it is too open, that it allows socially constructing technologies in ways that would not happen in reality. To put it differently, the question is what are the limitations of social construction? In the case of most extant and widely used technologies, there are a number of widely shared possible interpretations. A car, for example, can be used as a means of transport, a status symbol, or an investment. There are other, less frequent, uses such as the automobile as a place to sleep, as a weapon, or a means to block roads. At the same time, there are numerous interpretations of cars that one does not come across. Cars are not conceptualized as blankets, as educational toys, or as a means to get to the moon (even though in fiction all of these might be conceivable). For the case of AmI, one can conceive of interpretations of the technology as surveillance mechanism or an alleviator of chores. The question is whether one can exclude possible interpretations a priori (i.e., before the technology has been used).

One answer to this question is contained in the theory of affordances (Hutchby 2001). The theory of affordances was prominently put forward by James Gibson (1977). It is worth noting that for Gibson, affordances played a role in biology and the 
animal kingdom. His main interest in affordances relates to the psychology of perception. He suggests the definition that "affordance of anything is a specific combination of the properties of its substance and its surfaces taken with reference to an animal" (p. 67). This definition shows that Gibson's primary interest is in animal perception, but of course it applies to humans as well. An example he discusses in some depth is the affordance of sitting-on. In order for an object to have this affordance, the object has to display several properties. These include that it has to be sufficiently rigid, level, flat, extended, and-for humans-approximately of knee-height. An object displaying these properties allows humans to sit on them, independent of other properties, such as color, material, smell, etc.

The interesting characteristic of affordance is that it is a combination of subjective and objective properties that are not random. An object that does not have the properties does not afford sitting-on, but at the same time, a chair for humans would not afford sitting-on to giants. Gibson believes that affordances are real in the ontological sense (i.e., not subject to social construction). The problem here is that this would suggest that a specific combination of subject and object would have a clearly defined set of affordances. From a philosophical perspective this raises the question how we can know what the affordances are. And if we have no way of knowing whether we have identified a complete set of affordances, it furthermore raises the question whether there is a point of speaking of real and objective affordances if we cannot answer the previous question.

The theory of affordances has become popular among technologists, in particular among those who create and build systems such as specialists in human computer interaction (Gaver 2010). It is sometimes described as a way to develop new research avenues in established fields of technology research (Suthers 2006). Such research has to contend with the question whether affordances are real or whether they are socially constructed. In order to sidestep this philosophically difficult problem, the distinction between real and perceived affordances was introduced (Norman 1999). The point of this distinction is to explain the fact that individuals may not notice the presence of affordances of technologies, which for all intents and purposes renders these affordances irrelevant.

The problem of perceived affordances is that it reintroduces uncertainty into the description of technology that the theory of affordances was meant to overcome. If we are only interested in perceived affordances, then we have no objective measure that will allow us to determine whether a description of technology is complete. Affordances then become individual and reliant upon a number of accidental properties of the user, such as education, experience, age, etc. The affordance of a particular piece of software, for example, then changes between users and over time. In the case of technologies such as AmI, this raises additional problems given that one of the core features of AmI is its invisibility. It is thus possible to not notice it at all, which may imply that it has no affordances. In order to evade this trap, some sort of awareness raising or education will be required, which means that the affordances of the technology will depend not only on the technology itself and its users but also on the process of introducing the technology and the motivations of those who introduce it. 


\subsection{Multi-stability of Technology}

Don Ihde (1999) has developed a different terminology that is meant to address the same problem as that of technological affordances. Ihde argues that technology is multi-stable. His argument refers to the issue of technology prognosis and the role that philosophy can play in it. Retrospective evaluation of technology and its conesquences may be possible, but prospective work encounters the problem of multistability. By multi-stability he means that technology cannot take on any social role and use, thus addressing the problem of indefinite possibilities that arises from social constructivism and interpretive flexibility. But while the possibilities that exist are not infinite, they are still greater than one. Technology, once it develops, will become stable but which of a number of possible trajectories it takes is not foreseeable. This multi-stability refers to uses but also effects, side effects, and other outcomes.

The idea of trajectories within multi-stable technologies is the key to addressing the problem of prognosis. Ihde contends that full prognosis may be impossible, but that the trajectories are at least partially determined which can allow a limited prediction of possible futures.

\subsection{The Description and Prognosis of Emerging Technologies}

This position seems to suggest that it is possible to get some sort of acceptable handle on dealing with emerging ICTs. This section has discussed the problems of describing technologies. Using arguments from several backgrounds, it was argued that it is difficult to give a correct account of any technology, including the most widely spread ones. This difficulty is exacerbated when the object of investigation is no longer an existing technology but shifts to future technologies. The further the temporal horizon of investigation, the less clear the description becomes (Collingridge 1981).

With regards to our problem of AmI, we can now distinguish several aspects of the uncertainty of the concept. The uncertainty of AmI is partly explained by the interpretive flexibility, which means that the individual's view of the technology is not determined by his or her perceptions. This is all the more the case because AmI exists more as a concept than a present socio-technical reality. Because of this uncertainty, it is unclear what the affordances of AmI are. We have seen that there is disagreement about the ontological status of affordances (i.e., whether affordances are real properties of technologies or whether they are observer-dependent). Even if one were to concede that affordances are objective, the next problem would remain: that the developing nature of AmI make them difficult if not impossible to determine. This corresponds with Ihde's point about the multi-stability of technology. At present it is not possible to predict which trajectory AmI will take. While there is significant marketing activity which supports particular paths, it is unclear whether these will materialize.

The contribution of this section is to show that there are at least four different positions that seek to explain the same phenomenon, namely the impossibility of comprehensively describing technology and especially of finding a description of relevant futures. The paper does not claim that these are the only ways of framing the problem. It aims to underline, however, that all of these positions have some influence on the debate in information systems, but even collectively they have not sufficed to convince the field of the importance of addressing the problem. If we have no way of knowing 
whether a particular description of technology is the right one, then how can we do research on the technology and how can we make policy decisions that provide the basis of a desirable future?

\section{Participative Technology Assessment: A Way Forward?}

The problem of uncertainty of emerging technology cannot be solved in the same way a technical problem may be solved. The different perspectives outlined above all point to the inevitability of uncertainty. However, we still have to make decisions about the future, despite this uncertainty. There are numerous ways of doing this, all of which have different advantages and disadvantages. This paper suggests that there are established ways of dealing with technologies that can compensate for some of the uncertainties of emerging technologies. Specifically, the paper suggests that participatory technology assessment (pTA) can overcome some of the problems. As will be argued in more detail below, pTA can overcome the epistemological problem by broadening the knowledge base of new technologies. At the same time, it is based on democratic principles and therefore can contribute to the legitimacy of decisions based on the descriptions of technology, even where these may be contested.

pTA is a branch of technology assessment (TA) that uses participatory methodologies and approaches. TA has a long history, going back to the 1960s, as an institutionalized attempt to understand issues of science and technology. Much early TA work was inspired by the U.S. Office of Technology Assessment with many countries creating similar institutions at the parliamentary or governmental level with the specific remit of providing policy advice (Joss 2002). Much early TA work was expertcentered but, as the limitations of this expert-centered approach became obvious, participatory methods were increasingly employed. There are several competing concepts that cover the same area, such as constructive TA (Joss and Belucci 2002; Schot 2001; Schot and Rip 1996). For the purposes of this paper, the differences between these concepts are of secondary importance and we will, therefore, use the term pTA following Joss and Belucci's (2002, p. 5) definition that "the term 'participatory technology assessment' (pTA) refers to the class of methods and procedures of assessing socio-technological issues that actively involve various kinds of social actors as assessors and discussants." pTA has been established as a useful and legitimate way of undertaking TA. The cognitive, normative, and pragmatic benefits outlined above have given rise to significant experimentation with pTA to the point that there now is wide acceptance of its importance and contribution (Joss 2002).

Methodologies of pTA are not necessarily simple and clear-cut. They depend on a number of factors including the research question, intended outcomes, type of respondents, experience of facilitators, cultural background, and political embedding to name but a few. Methodologies need to be carefully tuned and customized for any specific project (Hennen 2002).

Having proposed pTA as the response to the problem of this paper, namely the appropriate description of emerging ICTs, it is worthwhile reviewing the pTA literature in order to cross-check whether the expected benefits have been identified by pTA practitioners and to assess whether work in the area has led to the identification of problems that can jeopardise the success of the approach. 


\subsection{Benefits of pTA}

Belucci et al. (2002) distinguish two main arguments in favor of participative work: pragmatic arguments that underline the function of participation as a means to improve decision making and normative arguments that underline the democratic aspect. These lines of arguments are linked to two main underlying problem areas: uncertainty and inequality. These lines of argument, while analytically different, are practically closely intertwined. A further dimension in addition to the pragmatic and the normative one is the cognitive.

The cognitive dimension has to do with knowledge of the problem area in question. Participation involves the individuals who are affected by the problem area and who have the most advanced local knowledge. By being able to tap into this often unused pool of local knowledge, a better understanding of the problem is developed. Genus and Cole (2005) hold that epistemological advantages of participation include an anticipation of impacts of technology, thus exhibits a move from reaction to proactive involvement. The "deep learning" that they associate with participation covers not only facts but also associated values. There is furthermore an aspect of reflexivity which ensures that the actors in participative projects develop a better understanding of their mutual roles and interests. The importance of this cognitive role of participation is caused by the often problematic role of the subject area. Political, social, or ethical implications of technology do not result from their design but from a combination of design features, meanings associated with them, and social and material structures and practices of implementation (Brey 2002).

An important aspect of the cognitive dimension is related to risk or dangers posed by the technology. The intensive discussion of technical risks during the last two decades (Beck 1986) indicates quite clearly that risks emanating from technologies are not objective and easily measurable entities but are intrinsically related to stakeholders' perceptions and beliefs. Identifying such risks, dangers, and uncertainties is therefore something that requires the involvement of stakeholders beyond the technical experts (Callon et al. 2009). At the same time it is beyond doubt that early addressing of risks would be desirable and in many cases would open more possibilities than attempting to fix problems after they arise. This requires a better understanding of problems as provided by the cognitive function of participation.

Participative engagement in science and technology can overcome cognitive closures by forcing different participants to take each others' views seriously. This helps overcome expert bias in that expert opinions are taken seriously as an important contribution to socially constructed knowledge but are recognized as one among several such sources (Klüver 2002). Participation requires mutual respect and effects mutual learning between different actors. This mutual learning is an important aspect and outcome of participative work, which may render it worthwhile even in those cases where manifest pragmatic outcomes such as measurable influence on policy making do not materialize (Hansen 2006).

This means that participation needs to play a central role not only in determining policy choices with regard to ICT, but also that it needs to start earlier, at the problem definition and framing stage. Emerging ICTs are by their nature uncertain and not clearly defined. Local knowledge and stakeholder engagement, the input of "hybrid 
forums" (Callon et al. 2009) are necessary to ascertain that the problems are appropriately understood and expressed before governance or policy can be considered.

This question of appropriate framing refers back to the earlier discussion of the nature of technology, to interpretive flexibility and multi-stability. The value of such a participative approach is therefore not only confined to research and policyoriented activity but has also been recognized by businesses that increasingly leverage user knowledge in product innovation (von Hippel 2006), thereby making use of the same underlying phenomenon.

In addition to the cognitive and epistemological advantages of participation, there are also political and normative advantages which lead to an increase in the legitimacy of policy. As Bütschi and Nentwich (2002) point out, despite the increased knowledge base, participative engagement in science and technology rarely leads to unforeseen or unforeseeable results. It can still provide important inputs by giving new ways of understanding the problem and bestowing legitimacy on decisions. This is based on the increasingly obvious political nature of science and technology (Callon et al. 2009) which requires decisions to gain political legitimacy. This legitimacy is achieved by giving a voice to those who are affected (Genus and Coles 2005), which ensures higher levels of acceptability of outcomes than purely expert-drive procedures (Hennen 2002).

One of the mechanisms that bestow higher levels of legitimacy on participatively arrived-at outcomes is that participation can be interpreted as a type of democratization. Democracy, along with freedom and justice, is a primary virtue of a good society, and it implies that citizens have an equal say in decisions (Brey 2008). Representative democracy as the main implementation of the democratic principle in modern democratic states runs into a number of problems, notably with regard to the representation of minorities (Callon et al. 2009). Other, more direct forms of democracy, as emulated in some methods of participation, can overcome this problem and thereby strengthen the legitimacy of outcomes.

At this point political mechanisms such as direct democracy and technical developments converge on the concept of empowerment. Technology has become a primary means of empowerment but at the same time leads to potential differences in empowerment (Brey 2008). Recognizing such issues is a task of participation.

In addition to the cognitive, normative, and pragmatic advantages, there seems to be another attraction of participation, which is its theoretical background. Participation is based on discursive exchanges and it can therefore build on the rich background of discourse theories. The range of discourse theories, including the notable examples of Habermas's and Foucault's views on discourse (Ashenden and Owen1999; Kelly 1994), provide scholars with a rich background from which to draw descriptions and conceptualizations. It points to a rich body of knowledge concerning empirical interventions and interpretations of discourses.

\subsection{Problems of Participative Technology Assessment}

The link to discourse theory can also serve to highlight some of the disadvantages and limitations of participative interventions in science and technology. The muchdiscussed differences between Habermas and Foucault, for example, can be used to identify problems of participative methods (Genus and Coles 2005). The nature of the 
discursive relationship among participants can determine the success of the overall intervention. The arguments in favor of participation are based on deliberative ideals which are rarely realized in practice (Hansen 2006). This lack of fulfilment of theoretical conditions can have a direct effect on the outcomes.

There are a number of problems that can arise in the course of participation. Discourses may take place in an environment where preconceived notions dominate all possible outcomes, thereby leading to an infinite regress of identical arguments. There can be skewed discourses based on differing levels of discursive abilities of participants or because of strategic interests of particular participants. Particular interests may attempt to highjack the discourse for their purposes.

But even if none of these situated and particular problems arise, it may still be the case that participation does not lead to the desired outcomes. This may be because some stakeholders are not available to participate and cannot be represented in an appropriate way. It may also be the case that no shared view of the problem emerges and not even an agreement on central disagreements is possible. The legitimacy of participation may be jeopardized when it is perceived to be in conflict with representative democracy. And finally, even in the positive case that the process fulfils the hopes invested in it, it is entirely possible that the outcomes are not clear-cut, recommendations are ambiguous, and answers remain vague.

Returning to the ongoing example of Ami, this discussion of pTA could be translated into an approach to participatively understand and shape AmI. This would require an appropriate mechanism of stakeholder involvement, which pTA can provide. On the basis of a representative and legitimate process, stakeholders could contribute their understanding of the technology as well as collectively develop a clearer picture of real and desired or undesired properties of the technology. Such a view would to some degree address the epistemological uncertainty surrounding AmI. More importantly, a participative approach might define roadmaps for a technology future that is deemed to be desirable and acceptable by the stakeholders. Such a roadmap could then provide the basis for democratic policy development. This scenario at the same time also shows the limitations of the approach. While collective action may claim a higher degree of knowledge, it is just as fallible as individual. The legitimacy of participative engagement can conflict with the legitimacy of representative democratic processes. There is thus no perfect solution. However, the example of AmI should have shown that we have a better chance of coming to technologies that are conducive to individual and social aims when we employ participative methods than if we continue to leave them purely in the hands of unsupervised market forces.

\section{Conclusion}

This paper was motivated by the apparent ease with which terms such as "future IT" or "emerging ICT" are used in public discourses, including the theme of this IFIP conference. It set out to explore the problems of this usage of terms. Drawing on several streams of the philosophy of technology and other theoretical arguments, it demonstrated that a correct, appropriate, or even true description of technologies is difficult to achieve. This is true in the case of existing and widely spread technologies, but even more so for technologies that are not yet fully developed and in some stage of emergence. 
The epistemological uncertainty of emerging technologies can be explained using concepts such as interpretive flexibility, affordances, or multi-stability. While such concepts are theoretically helpful in understanding the limitations of research on these technologies, they offer little practical recourse to overcome these problems. This is a significant problem because it renders obsolete any attempts to steer the development of technology in desired paths. This is true for high-level policy makers on a national or international level, but it raises similar issues for decision makers on a sectoral or organizational level. If we don't know what future technologies to expect, then how can we plan for them?

Drawing on the literature surrounding pTA, it was argued that the epistemological as well as the ethical issues raised by emerging ICTs can be addressed by means of pTA. This does not promise perfect solutions but it provides a way forward where otherwise the only solutions might have been to ignore the problem of emerging ICTs or to simply extrapolate past developments into the future.

The paper makes a significant contribution to the theoretical discourse on emerging ICTs and thereby to the field of IS. It brings together the main strands of debate: the epistemology of technology (i.e., interpretive flexibility, affordances, multi-stability), and the discourse surrounding pTA. This allows a better understanding of theoretical and conceptual issues that an evaluation of technology in general, and of emerging technology in particular, raise. It provides ways of crosspollination between these strands of discourse that improves our understanding of technology. It also points the way toward approaches and methodologies that will allow us to give answers to the difficult questions surrounding future technologies.

While the main contribution of the paper is of a theoretical nature, it has interesting implications for practice. If the argument of the paper holds, then this implies that improving our understanding of emerging ICTs will require engaging in participative methods of assessment. There are numerous such methods that have been explored, ranging from focus groups to consensus conferences or citizens' panels. What is less well explored is how these can be used for a range of problems to which they have not been applied. This refers in particular to the question of participation being organized on a local or company level.

The present paper thus points the way toward a rich and complex area of empirical research. Which participative methods are suitable and conducive for which type of technology? This is a question that should be of interest to decision makers in charge of technology policy on a range of levels. A further question is how this participative idea relates to other approaches. There are numerous ways of designing ICT that actively seek to include user and stakeholder views and positions. These include approaches such as human-centered and value-sensitive design, but also many of the more established methodologies that evolved from soft systems and related approaches. The theoretical and practical compatibility of these approaches are in need of investigation.

When technology assessment was in its infancy, much technology development was directly steered or undertaken by the state. This is no longer the case and certainly not in the area of ICTs. This raises the question whether participative interventions, such as the ones suggested here, can actually have a place and a practical outcome in the current socio-economic climate.

All of these questions are theoretically interesting and practically important. Together they can inform us whether we are still in control of technology development and how this control can be implemented in a transparent and democratic manner. 


\section{Acknowledgments}

The research leading to these results has received funding from the European Community's Seventh Framework Programme (FP7/2007-2013) under grant agreement no. [230318].

\section{References}

Adam, A.: Computer Ethics in a Different Voice. Information and Organization 11(4), 235-261 (2001)

Anscombe, G.E.M.: Modern Moral Philosophy. Philosophy 33(124), 1-19 (1958)

Ashenden, D.S., Owen, D.D.: Foucault Contra Habermas: Recasting the Dialogue between Genealogy and Critical Theory. Sage Publications Ltd, London (1999)

Beck, U.: Risikogesellschaft. Auf dem Weg in eine andere Moderne. Suhrkamp, Frankfurt (1986)

Belucci, S., Bütschi, D., Gloede, F., Hennen, L., Joss, S., Klüver, L., Nentwich, M., Peissl, W., Torgersen, H., van Eijndhoven, J., van Est, R.: Research Framework: Theoretical Perspectives, Analytical Framework, Research Protocol. In: Joss, S., Belluci, S. (eds.) Participatory Technology Assessment: European Perspectives, pp. 13-58. Centre for the Study of Democracy, University of Westminster, London (2002)

Bijker, W.E.: Of Bicycles, Bakelites, and Bulbs: Toward a Theory of Sociotechnical Change (Rev. Ed.). MIT Press, Cambridge (1997)

Brey, P.: The Technological Construction of Social Power. Social Epistemology 22(1), 71-95 (2008)

Bütschi, D., Nentwich, M.: The Role of Participatory Technology Assessment in the PolicyMaking Process. In: Joss, S., Belluci, S. (eds.) Participatory Technology Assessment: European Perspectives, pp. 235-256. Centre for the Study of Democracy, University of Westminster, London (2002)

Cadili, S., Whitley, E.A.: On the Interpretative Flexibility of Hosted ERP Systems. Journal of Strategic Information Systems 14(2), 167-195 (2005)

Callon, M., Lascoumes, P., Barthe, Y.: Acting in an Uncertain World: An Essay on Technical Democracy. MIT Press, Cambridge (2009)

Collingridge, D.: The Social Control of Technology. Palgrave Macmillan, London (1981)

Dusek, V.: Philosophy of Technology: An Introduction. Wiley Blackwell, Chichester (2006)

Gaver, W. W.: Technology Affordances [Internet]. In: Proceedings of the SIGCHI Conference on Human Factors in Computing Systems: Reaching through Technology, New Orleans, LA, pp. 79-84 (1991)

Genus, A., Coles, A.: On Constructive Technology Assessment and Limitations on Public Participation in Technology Assessment. Technology Analysis \& Strategic Management 17(4), 433-443 (2005)

Hutchby, I.: Technologies, Texts and Affordances. Sociology 35(2), 441-456 (2001)

Gibson, J.J.: The Theory of Affordances. In: Shaw, R.E., Bransford, J.D. (eds.) Perceiving, Acting and Knowing, pp. 67-82. Lawrence Erlbaum Associates, Hillsdale (1977)

Grint, K., Woolgar, S.: The Machine at Work: Technology, Work and Organization. Polity Press, Cambridge (1997)

Hansen, J.: Operationalizing the Public in Participatory Technology Assessment: A Framework for Comparison Applied to Three Cases. Science and Public Policy 1(33), 571-584 (2006) 
Hennen, L.: Impacts of Participatory Technology Assessment on its Societal Environment. In: Joss, S., Belluci, S. (eds.) Participatory Technology Assessment: European Perspectives, pp. 257-275. Centre for the Study of Democracy, University of Westminster, London (2002)

Howcroft, D., Mitev, N., Wilson, M.: What We May Learn from the Social Shaping of Technology Approach. In: Mingers, J., Willcocks, L.P. (eds.) Social Theory and Philosophy for Information Systems, pp. 329-371. Wiley, Chichester (2004)

Ihde, D.: Technology and Prognostic Sredicaments. AI \& Society 1(13), 44-51 (1999)

Joss, S.: Toward the Public Sphere-Reflections on the Development of Participatory Technology Assessment. Bulletin of Science Technology Society 1(22), 220-231 (2002)

Joss, S., Belucci, S.: Participatory Technology Assessment in Europe: Introducing the EUROPTA Research Project. In: Joss, S., Belluci, S. (eds.) Participatory Technology Assessment: European Perspectives, pp. 3-11. Centre for the Study of Democracy, University of Westminster, London (2002)

Kant, I.: Kritik der reinen Vernunft. Neuauflage, Studienausgabe, Suhrkamp (1995)

Kelly, M.: Critique and Power: Recasting the Foucault/Habermas Debate. MIT Press, Cambridge (1994)

Klüver, L.: Project Management: A Matter of Ethics and Robust Decisions. In: Joss, S., Belluci, S. (eds.) Participatory Technology Assessment: European Perspectives, pp. 179-208. Centre for the Study of Democracy, University of Westminster, London (2002)

Latour, B.: Reassembling the Social: An Introduction to ActorBNetwork Theory (Rev. Ed.). Oxford University Press, Oxford (2007)

Law, J., Hassard, J.: Actor Network Theory and After. Wiley Blackwell, Chichester (1999)

Norman, D.A.: Affordance, Conventions, and Design. Interactions 6(3), 38-43 (1999)

Olsen, J.B., Pedersen, S.A., Hendricks, V.F.: A Companion to the Philosophy of Technology. Wiley Blackwell, Chichester (2009)

Schot, J.: Towards New Forms of Participatory Technology Development. Technology Analysis \& Strategic Management 13(1), 39-52 (2001)

Schot, J., Rip, A.: The Past and Future of Constructive Technology Assessment. Technological Forecasting and Social Change 54(2/3), 252-268 (1996)

Suthers, D.: Technology Affordances for Intersubjective Meaning Making: A Research Agenda for CSCL. International Journal of Computer-Supported Collaborative Learning 1(3), 315337 (2006)

van den Hoven, J.: The Use of Normative Theories in Computer Ethics. In: Floridi, E.B.L. (ed.) The Cambridge Handbook of Information and Computer Ethics. Cambridge University Press, New York (2010)

von Hippel, E.: Democratizing Innovation. MIT Press, Cambridge (2006)

\section{About the Author}

Bernd Carsten Stahl is Professor of Critical Research in Technology and Director the Centre for Computing and Social Responsibility at De Montfort University, Leicester, UK. His interests cover philosophical issues arising from the intersections of business, technology, and information, including the ethics of computing and critical approaches to information systems. From 2009 to 2011, he served as coordinator of the EU FP7 research project "Ethical Issues of Emerging ICT Applications" (ETICA) (GA 230318, www.etica-project.eu). 